\title{
COMPROMETIMENTO ORGANIZACIONAL: CONFRONTANDO O COMPROMETIMENTO AFETIVO E INSTRUMENTAL ENTRE TRABALHADORES AUTÔNOMOS E EFETIVOS DE SALÕES DE BELEZA
}

\author{
D. M. VENÂNCIO ${ }^{1 *}$, A. DUTRA ${ }^{2}$, G. G. S. FIATES ${ }^{1}$ e S. G. FEUERSCHÜTTE ${ }^{3}$ \\ ${ }^{1}$ Universidade Federal de Santa Catarina - UFSC \\ ${ }^{2}$ Universidade do Sul de Santa Catarina - UNISUL \\ ${ }^{3}$ Universidade do Estado de Santa Catarina - UDESC \\ dani@fuzz.com.br*
}

Artigo submetido em junho/2013 e aceito em abril/2015

DOI: $10.15628 /$ holos.2015.1525

\section{RESUMO}

Este artigo tem como objetivo analisar as diferenças do comprometimento afetivo e instrumental entre trabalhadores autônomos e efetivos de salões de beleza localizados na grande Florianópolis em Santa Catarina, Brasil. Trata-se de um estudo descritivo e exploratório, de natureza quantitativa e com um corte transversal, envolvendo cinco salões de beleza. A partir dos resultados obtidos percebe-se que (i) as funções com atividades mais rotineiras, menos desafiantes e que exigem uma menor variedade de habilidades, tendem a diminuir o comprometimento do trabalhador; (ii) os maiores índices de comprometimento referem-se à função de depiladora, com 6,45 (vínculo efetivo), e esteticista com 5,87 (vínculo autônomo); (iii) trabalhadores autônomos e efetivos apresentam médias de comprometimento organizacional similares, sendo que os autônomos são mais comprometidos afetivamente $(5,31)$ do que os efetivos $(5,05)$; (iv) não existem diferenças estatísticas significativas no grau de comprometimento organizacional afetivo e instrumental entre trabalhadores autônomos e efetivos; e (v) não é possível generalizar conceitos que possam relacionar comprometimento organizacional com contrato de trabalho.

PALAVRAS-CHAVE: gestão de pessoas; comprometimento organizacional; contratos de trabalho; salões de beleza.

\section{ORGANIZATIONAL COMMITMENT: CONFRONTING AFFECTIVE AND INSTRUMENTAL COMMITMENT BETWEEN BEAUTY SALONS SELF-EMPLOYED AND REGULAR HIRED EMPLOYEES}

\begin{abstract}
This article's objective is to evaluate the differences between self-employed and employees regarding affective commitment and also instrumental commitment. It contains a descriptive and explanatory study with quantitative and cross-section analysis concerning five beauty salons located in Florianópolis' region, in Santa Catarina. From the given results, (i) everyday activities that are less challenging and don't require special skills drives to a decrease in the worker's commitment; (ii) the biggest commitment levels are found among waxing specialists with 6,45 (affective
\end{abstract}

commitment) and estheticians with 5,87 (autonomous commitment); (iii) self-employed and employees present similar average organizational commitment, nevertheless, the first group is more affective committed $(5,31)$ than the second one $(5.05)$; (iv) there is no signifficant statistical difference in organizational and practical commitment among self-employeds and employees; and (v) it's not possible to generalize concepts that may establish a final relation between organizational commitment and working agreement.

KEYWORDS: people management, organizational commitment, work contracts; salon. 


\section{INTRODUÇÃO}

Dentro do campo de estudos do comportamento organizacional, um dos temas que vem atraindo os pesquisadores nos últimos vinte anos é o comprometimento organizacional (COSTA; BASTOS, 2009). As pesquisas que investigam o comprometimento organizacional buscam descobrir bases de um padrão comportamental desejável nas organizações, como lealdade, permanência e a famosa expressão "vestir a camisa" (BORGES-ANDRADE, 1994).

O comprometimento é um tema em construção na literatura, contudo ele vem sendo investigado em duas bases distintas; a atitudinal, que apoia-se nas teorias da psicologia e investiga os sentimentos positivos e negativos que os trabalhadores nutrem pela organização; e a cognitiva, que indaga o comprometimento a partir de indicadores comportamentais vistos como vantagens percebidas pelos indivíduos por permanecerem na organização (SIQUEIRA; GOMIDE JÚNIOR, 2004).

Allen e Meyer (1991) evidenciam o comprometimento organizacional por meio de três tipos: um de base afetiva, o afetivo; e dois de base cognitiva, o instrumental e o normativo. As tipologias afetiva e instrumental são as mais investigadas na literatura (MEDEIROS, 1997). 0 tipo afetivo está associado ao elo emocional e à identificação do trabalhador com a organização na qual atua; o tipo instrumental está vinculado às perdas financeiras ou benefícios relacionados à saída do trabalhador da organização (ALLEN; MEYER, 1991).

$\mathrm{Na}$ esfera organizacional existem profissionais atuando em diversos regimes de contratação, como, por exemplo, estagiários, terceirizados, celetistas, funcionários públicos, dentre outros. Dentro desse cenário, no Brasil, temos os salões de beleza. Nesse tipo de organização é habitual encontrar indivíduos atuando com diferentes contratos de trabalho, sendo os mais usuais: o efetivo e o autônomo. Os efetivos possuem contratos de trabalho regidos pela CLT (Consolidação das Leis de trabalho), e os autônomos, contratos de parceria ou de locação de espaço (MELCHOR, 2012). Interessa compreender se a forma de contratação interfere no comprometimento desses profissionais com seus respectivos salões de beleza, já que independentemente do tipo de contrato de trabalho acordado entre o trabalhador e a organização, anseia-se que o comprometimento seja uma variável presente no dia a dia de qualquer organização (COHEN, 2003).

Embasando-se na realidade de indivíduos que trabalham com diferentes contratos de trabalhos, como é o caso dos profissionais autônomos e efetivos que atuam em salões de beleza, levanta-se a pergunta que norteará a presente pesquisa: Qual a diferença do comprometimento organizacional afetivo e instrumental entre trabalhadores autônomos e efetivos de salões de beleza?

Para responder tal problemática, tem-se o seguinte objetivo geral: confrontar o grau de comprometimento organizacional afetivo e instrumental entre trabalhadores autônomos e efetivos em salões de beleza localizados na grande Florianópolis. Para alcançar o objetivo geral, foram elaborados como objetivos específicos: i) descrever as medidas de comprometimento organizacional afetivo e instrumental dos profissionais autônomos e efetivos; e ii) analisar comparativamente as medidas de comprometimento instrumental e afetivo de acordo com a função ocupada. 
O Brasil está entre os três países que mais consome produtos e serviços ligados à beleza no mundo (ASSOCIAÇÃO BRASILEIRA DA INDÚSTRIA DE HIGIENE PESSOAL, PERFUMARIA E COSMÉTICOS, 2011). No entanto, percebe-se uma lacuna no que diz respeito à investigação do comportamento das pessoas que trabalham nessa área da economia. Diante do exposto, e entendendo a relevância de ampliar a investigação sobre comprometimento organizacional, a presente pesquisa tem a intenção de estabelecer uma maior compreensão de como se articulam os vínculos dos profissionais que atuam com diferentes tipos de contrato de trabalho.

\section{COMPROMETIMENTO ORGANIZACIONAL}

Para Menezes (2009), é difícil precisar ao certo o primeiro conceito que se tornou central para a investigação do comprometimento organizacional. Porém, Kelman (1958) é citado por diversos autores (ALLEN; MEYER, 1991; BASTOS, 1993; MEDEIROS, 1997; SIQUEIRA, 2001; MEDEIROS et al., 2003; MENEZES, 2009; BASTOS, 2009) como um dos primeiros pesquisadores a contribuir com o tema comprometimento organizacional.

Kelman (1958) definiu o comprometimento organizacional em três bases distintas: i) complacência/compliance: envolvimento instrumental, motivado por recompensas extrínsecas; ii) identificação/identification: envolvimento baseado num desejo de afiliação; e o terceiro iii) internalização/internalization: envolvimento causado pela coerência entre os valores individuais e organizacionais.

Becker (1969) também é considerado como um dos pioneiros sobre o estudo do comprometimento organizacional (ALLEN; MEYER, 1991; BASTOS, 1993; MEDEIROS, 1997; SIQUEIRA, 2001; MEDEIROS et al., 2003; MENEZES, 2009; BASTOS; MENEZES, 2009). De acordo com esse autor, o comprometimento diz respeito ao "engajamento em linhas consistentes de ação" (BECKER, 1969, p. 33) e envolve três elementos centrais: i) persistência do comportamento durante um período de tempo significativo; ii) rejeição de alternativas de trabalho; e iii) perseguição de uma meta, não obstante a adversidade externa.

No final da década de 70, os estudos sobre o comprometimento organizacional ganharam notoriedade com o trabalho de Mowday, Steers, Porter (1979). Os autores definiram o comprometimento a partir de três dimensões: a aceitação dos valores, normas e objetivos da organização, a disposição de investir esforços em favor da organização e o desejo e a vontade de permanecer na organização. No Brasil, esse modelo foi validado por Borges-Andrade, Afanasief e Silva (1989).

Diversos autores concordam que o comprometimento organizacional é um conceito em evolução no campo do comportamento organizacional (ALLEN; MEYER, 1991; BASTOS, 1993; MEDEIROS, 1997; SIQUEIRA, 2001; MEDEIROS et al., 2003; SIQUEIRA; GOMIDE JÚNIOR, 2004; MENEZES, 2009; BASTOS; MENEZES, 2009). Entretanto, na literatura, um dos conceitos em destaque é o desenvolvido por Allen e Meyer (1991), que evidencia o comprometimento organizacional por meio de três tipos: o afetivo, o instrumental e o normativo (SIQUEIRA; GOMIDE, 2004; COSTA, 2005; SOLDI, 2006; MEDEIROS; ENDERS, 1998; ZANELLI; SILVA, 2008; MENDES; ZATTI, 2007). No entanto, Cooper-Hakim e Viswesvaran (2005) conduziram uma metaanálise e revelaram uma forte correlação entre os comprometimentos afetivo e normativo. 
No Brasil, Bastos (2004), Medeiros (1997), Menezes (2009) e Moscon (2009) também observam uma similitude entre o comprometimento afetivo e normativo, esses autores reafirmam o fato de o comprometimento normativo estar inserido no comprometimento afetivo. De modo a considerar as investigações citadas, esta pesquisa investigará o comprometimento organizacional entre profissionais autônomos e efetivos dos salões de beleza utilizando a tipologia afetiva e o instrumental.

\subsection{Comprometimento afetivo e instrumental}

O tipo afetivo é o que recebe maior destaque na literatura sobre o comprometimento organizacional (MEDEIROS et al., 2003). Essa tipologia tem suas raízes nas teorias organizacionais de Etzioni (1961, apud Bastos, 1993). O autor investigou como se forma o vínculo estabelecido entre o indivíduo com a organização. Etzioni sugeriu três diferentes tipos de envolvimento: i) moral, quando o indivíduo envolvido aceita as metas da organização e se identifica com elas por uma questão moral; ii) calculativo, quando o vínculo se dá pelas trocas estabelecidas com a organização; e iii) alienativo, quando o envolvimento ocorre devido à falta de alternativas ou quando o trabalhador permanece na organização por se sentir aprisionado a ela.

A tipologia afetiva foi aprimorada através de trabalhos de Mowday, Steers e Porter (1982). Para esses autores, o comprometimento ultrapassa a lealdade passiva para com a organização e envolve um relacionamento que busca um "sentir-se bem" na organização. Os autores supracitados montaram e validaram um instrumento de pesquisa para medir o comprometimento organizacional, chamado Organizational Commitment Questionnaire (OCQ).

No que tange ao tipo instrumental, os estudos de Becker (1969) são apontados pelos estudiosos da área como a origem do comprometimento instrumental (BASTOS, 1994; MEDEIROS, 1997; TAMAYO et al., 2001; SIQUEIRA, 2001; MEDEIROS et al., 2003; SIQUEIRA; GOMIDE JÚNIOR, 2004; COSTA; BASTOS, 2009). Becker (1969) desenvolveu uma teoria intitulada pelo tema de side-bets. Segundo o autor, o comprometimento diz respeito ao "engajamento em linhas consistentes de ação" (BECKER, 1969, p. 33) e envolve três elementos centrais: persistência do comportamento durante um período de tempo significativo; rejeição de alternativas de trabalho; e perseguição de uma meta, não obstante a adversidade externa. Para Becker (1969), um indivíduo permanece vinculado a uma organização devido a sua necessidade de se ajustar individualmente em posições sociais e também devido aos custos e benefícios associados a sua saída. Mais tarde, outros cientistas nomearam esse mesmo conceito como comprometimento calculativo, continuação e instrumental.

Costa (2005) afirma que o comprometimento instrumental de um empregado com a organização pode ser entendido pelo ato de o indivíduo nela permanecer e por conta de percepções individuais sobre investimentos feitos e resultados alcançados na organização. Para avaliar o comprometimento instrumental, Ritzer, Trice (1969), Hrebiniak e Alluto (1972) desenvolveram duas escalas que questionam os trabalhadores sobre a probabilidade de deixarem a organização para a qual trabalham por outra empresa em função de vantagens como: aumento de salário, elevação de status, oportunidade de crescimento, etc. Allen e Meyer (1991) também desenvolveram uma escala que avalia o comprometimento instrumental, sendo essa a mais utilizada pelos pesquisadores da área. 


\subsection{Contratos de trabalho e o comprometimento organizacional}

A revolução tecnológica e o advento da globalização têm criado novas formas de trabalho que não se limitam ao conceito clássico de emprego. De acordo com Nascimento (2010), o trabalhador autônomo tem ganhado notoriedade na sociedade contemporânea, já que os sistemas de produção de bens, serviços e informações criaram novas realidades com reflexos visíveis nas formas em que os trabalhos são prestados.

De acordo com o Sindicato dos Institutos de Beleza e Cabeleireiros do Rio de Janeiro (SINBEL, 2012), grande parte da mão de obra contratada nos salões de beleza é de trabalhadores autônomos, no entanto também existem profissionais admitidos com carteira assinada, com contratos regidos pelo CLT (Consolidação das Leis Trabalhistas). Geralmente, possuem carteira assinada pessoas que desempenham funções como: recepcionista, telefonista, estoquista, serviços gerais, manobrista, gerentes, supervisores, caixa, dentre outras funções administrativas. Já os profissionais autônomos são aqueles que prestam serviços, como: manicures, cabeleireiros, barbeiros, esteticistas, maquiadores e depiladores. Os profissionais autônomos recebem um percentual sobre sua produção, cada salão de beleza tem seu valor de repasse bem como um modelo de contrato de parceria específico.

Dentro da área do comportamento organizacional, a literatura apresenta colaborações acerca do comprometimento organizacional entre trabalhadores com diferentes tipos de contrato de trabalho. Costa (2005) caracterizou como se estruturam os vínculos de comprometimento com o trabalho e a organização e a sua relação com a natureza dos contratos de trabalho entre trabalhadores de organizações agrícolas. Os resultados apontaram que os trabalhadores temporários que trabalhavam pela primeira vez na empresa, de maneira geral, eram menos comprometidos com a organização. Os trabalhadores temporários apresentaram um grau de comprometimento instrumental mais elevado do que os trabalhadores permanentes.

Soldi (2006) comparou o grau de comprometimento organizacional entre empregados terceirizados e efetivos que trabalham numa mesma organização. Os efetivos apresentam graus mais elevados de comprometimento afetivo, enquanto, na média, os terceirizados apresentam graus mais elevados de comprometimento instrumental e normativo.

Leite (2004) identificou a intensidade, natureza predominante do comprometimento organizacional dos servidores técnicos administrativos do quadro permanente e temporário com a Universidade Estadual do Sudoeste da Bahia. Os resultados sugerem que os servidores do quadro temporário possuem um grau de comprometimento maior do que aqueles do quadro permanente na maioria das associações feitas com as demais variáveis.

Mendes e Zatti (2007) avaliaram o grau de comprometimento de enfermeiras com diferentes vínculos empregatícios em relação à organização hospitalar. Os resultados revelam que, em relação ao comprometimento com a organização, as enfermeiras estatutárias apresentam graus discretamente mais elevados. Na base afetiva, os dois grupos não apresentaram diferenças; já na base instrumental, as enfermeiras contratadas apresentam graus mais elevados de comprometimento; na base normativa, as enfermeiras estatutárias mostraramse mais comprometidas.

Bastos e Rowe (2010) analisaram o comprometimento com a carreira e com a produção acadêmica entre docentes do ensino superior, comparando o contexto público e o privado. Os 
autores verificaram que os docentes das instituições privadas apresentam maior comprometimento instrumental do que os docentes de instituições públicas. Estes dedicam-se mais à pesquisa do que aqueles.

Alguns estudiosos da área do comprometimento (MEYER et al., 1998; COHEN, 2003; BASTOS, 2004) afirmam que o comprometimento organizacional pode receber influência direta do tipo de contrato de trabalho estabelecido entre o trabalhador e o empregador. Entretanto, outros (MEDEIROS et al., 2003; COSTA, 2005) recomendam a investigação do comprometimento organizacional em trabalhadores com diferentes contratos de trabalho em distintos setores da economia, já que cada área possui suas peculiaridades.

\section{METODOLOGIA DE PESQUISA}

A estratégia de pesquisa adotada é a survey, uma vez que ela utiliza informações de um determinado grupo, trabalhadores que atuam em salões de beleza, a partir da aplicação de questionários. Trata-se um estudo descritivo e exploratório por buscar maior compreensão da possível relação entre o comprometimento e o tipo de contrato de trabalho firmado entre os profissionais e seus devidos salões de beleza. O horizonte de tempo é transversal, uma vez que foi aplicado em um único e curto período.

Para medir o comprometimento afetivo e instrumental, utilizou-se a escala proposta por Meyer e Allen (1997), com 06 itens para cada base, totalizando 12 itens. As bases foram validadas no contexto nacional por Medeiros e Enders (1997), que encontraram os valores de alfa de Cronbach para o fator afetivo $\alpha=0,68$ e para o instrumental de $\alpha=0,61$. A presente pesquisa obteve um alfa de 0,77 para o fator afetivo e de $\alpha=0,68$ para o instrumental.

\subsection{Amostra}

Os dados foram coletados em cinco salões de beleza de médio porte na cidade de Florianópolis, Santa Catarina. A amostra total foi de 192 trabalhadores, dos quais 135 (70,31\%) têm contrato de trabalho autônomo e 57 (29,69\%) trabalham como efetivos. Foram utilizados questionários estruturados como instrumentos de coleta. Observa-se forte predomínio do sexo feminino na composição dos participantes da pesquisa, tanto entre os trabalhadores efetivos $(87,72 \%)$ quanto entre os autônomos $(80,74 \%)$.

\subsection{Análise de dados}

O processo de tabulação dos dados foi realizado com a digitação das respostas em planilhas do Microsoft Excel. Na sequência, a análise dos dados foi realizada por meio do software IBM SPSS Statistics (versão 2.0). Em seguida, foram revisados e excluídos os missing value. A pesquisa também utilizou a análise de variância ANOVA para avaliar as diferenças entre as médias nos dois grupos, autônomos e efetivos. Para realizar a análise da diferença entre as médias de comprometimento afetivo entre profissionais autônomos e efetivos, foi necessária a formulação das seguintes hipóteses: $\mathrm{H}_{0}$ (hipótese nula) - não há diferença no comprometimento entre autônomos e efetivos; e $\mathrm{H}_{1}$ (hipótese alternativa) - há diferença no comprometimento entre autônomos e efetivos. 


\section{DISCUSSÃO DOS RESULTADOS}

Nesta etapa da pesquisa, foi feita a descrição e análise dos resultados obtidos, sendo a ordem de apresentação: (i) média de comprometimento por função ocupada; (ii) média de comprometimento afetivo e instrumental em profissionais autônomos e efetivos; e por fim a (iii) comparação dos resultados dos graus de comprometimento dos profissionais autônomos e efetivos frente ao comprometimento afetivo e instrumental.

Utilizou-se a terminologia adotada por Costa (2005): escores inferiores a 4,00 serão tratados como baixo comprometimento; de 4,00 a 5,50, moderado comprometimento; e acima de 5,50, elevado comprometimento.

\subsection{Média de comprometimento por função ocupada}

A variável função é uma característica relativa ao trabalho que, segundo alguns autores, pode influenciar nos níveis de comprometimento afetivo e instrumental (MOWDAY et al., 1982; MATHIEU; ZAJAC, 1990; MEYER et al., 2002; TAMAYO et al., 2001; COSTA, 2005). Confrontando as médias dos grupos por "função", encontrou-se um $p$-value $<0,05$, o que indica a existência de diferenças estatisticamente significantes. A Tabela 1 aponta as médias encontradas de acordo com a função ocupada e o tipo de contrato de trabalho.

Tabela 1 - Comprometimento x função

\begin{tabular}{|c|c|c|c|c|c|c|c|}
\hline FUNÇÃO & $\begin{array}{c}\text { NT* } \\
\mathbf{1 9 2}\end{array}$ & $\begin{array}{c}\text { NE } \\
* * \\
\mathbf{5 7}\end{array}$ & $\begin{array}{c}\text { NA } \\
* * * \\
\mathbf{1 3 5}\end{array}$ & \multicolumn{2}{|c|}{$\begin{array}{c}\text { COMPROMETIMENTO } \\
\text { AFETIVO } * * * * *\end{array}$} & \multicolumn{2}{c|}{$\begin{array}{c}\text { COMPROMETIMENTO } \\
\text { INSTRUMENTAL*** }\end{array}$} \\
\hline & $\%$ & $\mathbf{\%}$ & $\%$ & Efetivo & Autônomo & Efetivo & Autônomo \\
\hline CABELEIREIRO & 24 & 2 & 32 & 4,67 & 5,42 & 1,67 & 3,02 \\
\hline $\begin{array}{c}\text { AUXILIAR DE } \\
\text { CABELEIREIRO }\end{array}$ & 9 & 4 & 12 & 4,42 & 5,35 & 2,23 & 2,97 \\
\hline MANICURE & 22 & 0 & 30 & N/A & 5,19 & N/A & 3,18 \\
\hline PODÓLOGA & 2 & 0 & 3 & N/A & 4,96 & N/A & 2,63 \\
\hline ESTETICISTA & 3 & 0 & 4 & N/A & 5,87 & N/A & 2,67 \\
\hline MAQUIADOR & 8 & 7 & 8 & 4,97 & 5,29 & 2,96 & 3,39 \\
\hline FISIOTERAPEUTA & 1 & 0 & 2 & N/A & 4,00 & N/A & 2,50 \\
\hline DEPILADORA & 4 & 2 & 5 & 6,45 & 5,52 & 5,70 & 2,74 \\
\hline RECEPCIONISTA & 12 & 40 & 1 & 4,53 & 4,49 & 3,24 & 3,28 \\
\hline TELEFONISTA & 1 & 2 & 0 & 3,83 & N/A & 4,50 & N/A \\
\hline $\begin{array}{c}\text { FUNÇÕES } \\
\text { ADMINISTRATIVAS }\end{array}$ & 5 & 18 & 0 & 6,08 & N/A & 2,95 & N/A \\
\hline AUXILIAR DE LIMPEZA & 4 & 9 & 0 & 5,37 & N/A & 3,63 & N/A \\
\hline $\begin{array}{c}\text { OUTRA FUNÇÃO } \\
\text { (MANOBRISTA, GARÇOM } \\
\text { E ESTOQUISTA) }\end{array}$ & 5 & 5 & 1 & 5,73 & 5,33 & 3,85 & 3,00 \\
\hline
\end{tabular}

*NT= número total da amostra;

**NE= número de efetivos na amostra;

$* * * \mathrm{NA}=$ número de autônomos na amostra;

$* * * * \mathrm{p}<0,05$.

$\mathrm{Na}$ amostra nota-se uma grande disparidade entre os grupos efetivos e autônomos, pois entre os trabalhadores autônomos há maior proporção nas funções de cabeleireiro(a) $(33,33 \%)$ e 
manicure (31,11\%), que somados representam mais de $60 \%$ dos colaboradores autônomos em atividade nos salões de beleza. Porém, para o grupo de colaboradores efetivos, essas mesmas ocupações juntas representam menos de $2 \%$ dos trabalhadores.

O mesmo ocorre de modo inverso para as ocupações de recepcionista e funções administrativas, entre os efetivos essas ocupações representam mais de $50 \%$ dos colaboradores com carteira assinada, porém elas não representam $1 \%$ dos trabalhadores autônomos, ficando assim evidente que a proporção de trabalhadores efetivos está concentrada nas ocupações de recepcionista e funções administrativas, e a de trabalhadores autônomos, nas ocupações de cabeleireiro e manicure.

As funções de manicure, podóloga, esteticista e fisioterapeuta não foram encontradas no grupo de trabalhadores efetivos, já o grupo de trabalhadores autônomos não contava com profissionais como telefonistas, auxiliar de limpeza, com funções administrativas, etc.

Os cabeleireiros apontam escores de comprometimento afetivo $(5,42)$ e instrumental $(3,02)$. Os auxiliares de cabeleireiros são $9 \%$ da amostra (19 trabalhadores), a maioria é autônomo (17\%) e a minoria é efetivo (2\%). Os autônomos apresentam médias de comprometimento afetivo $(5,35)$ e instrumental $(2,97)$ superiores a dos profissionais efetivos.

A função manicure não traz profissionais efetivos, nesse grupo percebe-se um nível moderado de comprometimento afetivo $(5,19)$ e fraco de instrumental $(3,18)$.

Podóloga e fisioterapeuta são 3\% da amostra total, ambas as funções apresentam baixo comprometimento afetivo e instrumental quando comparadas com outras funções. A função maquiador representa $8 \%$ do total da amostra, constatam-se efetivos e autônomos. Os efetivos apresentaram uma média inferior de comprometimento afetivo $(4,97)$ em comparação com os autônomos $(5,29)$. Nos escores de comprometimento instrumental, efetivos $(2,96)$ e autônomos $(3,39)$. As depiladoras apresentam escores altos de comprometimento afetivo, as efetivas $(6,45)$ e autônomas $(5,52)$.

Recepcionistas e telefonistas representam $40 \%$ da amostra dos efetivos, sendo que as recepcionistas apresentam média moderada de comprometimento afetivo $(4,53)$ e as telefonistas baixa $(3,83)$. O comprometimento instrumental das recepcionistas também foi baixo, sendo $(3,24)$ para as efetivas e $(3,28)$ para as autônomas. Já os telefonistas apresentaram comprometimento instrumental moderado $(4,50)$.

Funções administrativas ocupam 5\% da amostra total e $18 \%$ da amostra dos efetivos. Comparando-se com outros grupos de efetivos, como recepção, essa função apresenta médias elevadas de comprometimento afetivo $(6,08)$.

Manobrista, garçom e estoquista representam 5\% do geral da amostra e apresentaram escores próximos à média geral de comprometimento encontrada na pesquisa, $(5,45)$ para o afetivo, $(3,86)$ para o instrumental.

A presente pesquisa aponta manicures, recepcionistas e telefonistas como menos comprometidas com a organização. Mathieu e Zajac (1990) afirmam que funções com atividades mais rotineiras, menos desafiantes e que exigem uma menor variedade de habilidades tendem a diminuir o comprometimento do trabalhador. Esse é o caso das manicures e recepcionistas. As manicures atendem, em média, um cliente a cada 40 minutos, e as etapas do serviço prestado são executadas sempre na mesma ordem (retirar o esmalte, lixar unhas, tirar cutículas e pintar 
unhas), fazendo com que o trabalho seja repetitivo, além de inadequado ergonomicamente, haja vista o número de profissionais que sofrem de dores e lesões relacionadas ao seu ofício.

As recepcionistas, por sua vez, também enfrentam uma rotina que pode parecer pouco estimulante em relação ao tempo de trabalho empregado e rendimento quando comparado a outros profissionais que desempenham serviços de beleza. Adiciona-se a isso o fato de esta função não ter, na maioria dos estabelecimentos, plano de carreira que motive a permanência desse profissional. Por desejar uma maior oportunidade de ganho, muitas recepcionistas estudam para ingressar na própria área de serviços de salão ou outro posto de trabalho remunerado por produção.

\subsection{Confrontando o comprometimento organizacional instrumental e efetivo entre profissionais autônomos e efetivos.}

No que tange aos trabalhadores autônomos, a análise descritiva aponta para o comprometimento afetivo, uma média de $(5,31)$ e um desvio padrão de $(1,08)$. No que diz respeito ao comprometimento instrumental, a média encontrada foi de $(3,04)$ e um desvio padrão de $(1,17)$.

Com relação aos trabalhadores efetivos, no comprometimento afetivo, encontrou-se uma média de $(5,04)$ e um desvio padrão de $(1,48)$; já para o comprometimento instrumental, os efetivos apresentaram uma média de $(3,35)$ e um desvio padrão de $(1,47)$.

Os dados descritos acima demonstram que ambos os grupos (autônomos e efetivos) apresentam médias de comprometimento organizacional afetivo moderadas, sendo que aparentemente os autônomos são mais comprometidos afetivamente $(5,31)$ do que os efetivos $(5,05)$. Segundo Siqueira e Gomide Júnior (2004), trabalhadores com maiores níveis de comprometimento afetivo internalizam os valores da organização, identificam-se com papéis do trabalho e possuem um desejo de permanecer na organização por terem uma ligação emocional forte com a empresa e com as pessoas envolvidas no contexto do trabalho.

Com relação ao comprometimento organizacional instrumental, os dois grupos apresentam uma média baixa de comprometimento, sendo que os efetivos $(3,35)$ são mais comprometidos instrumentalmente do que os autônomos (3,05). Allen e Meyer $(1991$, p. 3) afirmam que "empregados com forte comprometimento instrumental permanecem na organização por que precisam". Nesse mesmo sentido, Bastos (2009) cita que trabalhadores com elevados níveis de comprometimento instrumental permanecem na organização por razões alheias a sua vontade. As médias baixas encontradas em ambos os grupos sugerem que em geral os trabalhadores autônomos e efetivos permanecem nos salões de beleza não apenas por falta de oportunidade em outras empresas, mas por dificuldade de mudança, principalmente no caso dos autônomos, já que, quando esses profissionais mudam de salão de beleza, nem sempre os clientes os acompanham, a mudança de empresa, num primeiro momento, pode significar uma baixa em seus rendimentos.

Para analisar se as médias encontradas nos dois grupos de trabalhadores, efetivos e autônomos, são significativas estatisticamente, foram feitas análises de variância ANOVA. Para realizar a análise da diferença entre as médias de comprometimento afetivo e instrumental entre 
profissionais autônomos e efetivos, fez-se necessária a formulação das hipóteses descritas abaixo.

- $\mathrm{H}_{0}$ (hipótese nula) - não há diferença no comprometimento entre autônomos e efetivos.

- $\mathrm{H}_{1}$ (hipótese alternativa) - há diferença no comprometimento entre autônomos e efetivos.

Quando os dados mostram evidência suficiente de que a hipótese nula $\left(H_{0}\right)$ é falsa, o teste a rejeita, aceitando em seu lugar a chamada hipótese alternativa, $\left(\mathrm{H}_{1}\right)$. Contudo, para refutar a $\mathrm{H}_{0}$, é necessário verificar se os dados fornecem evidência suficiente, isso, em estatística, significa aplicar um teste de significância. É comum aplicar um padrão de significância de 0,05 (p-valor). Portanto, se $p \geq 0,05$ não existe evidência contra a $H_{0}$, nesse caso, aceita-se a $H_{0}$; se $p<0,05$, existe evidência significativa contra a $\mathrm{H}_{0}$, assim é possível rejeitar a hipótese nula (BARBETTA, 2004).

Na Tabela 2, podem-se verificar as informações necessárias para analisar as características das médias obtidas.

Tabela 2 - Resultado teste ANOVA

\begin{tabular}{|c|c|c|c|c|c|c|}
\hline \multicolumn{7}{|c|}{ ANOVA } \\
\hline & $\begin{array}{c}\text { Soma dos } \\
\text { Quadrados }\end{array}$ & Df & $\begin{array}{c}\text { Média dos } \\
\text { Quadrados }\end{array}$ & F & Sig. \\
\hline $\begin{array}{c}\text { COMPROMETIMENTO } \\
\text { AFETIVO }\end{array}$ & $\begin{array}{c}\text { Entre } \\
\text { Grupos }\end{array}$ & 2,85 & 1 & 2,85 & 1,91 & 0,16 \\
\hline & $\begin{array}{c}\text { Nos } \\
\text { grupos }\end{array}$ & 282,98 & 190 & 1,48 & & \\
\hline $\begin{array}{c}\text { Cotal } \\
\text { INSTRUMENTAL }\end{array}$ & $\begin{array}{c}\text { Entre } \\
\text { Grupos }\end{array}$ & 3,75 & 1 & 3,74 & 2,31 & 0,13 \\
\hline & $\begin{array}{c}\text { Nos } \\
\text { grupos }\end{array}$ & 309,65 & 190 & 1,63 & & \\
\hline & Total & 313,42 & 191 & & & \\
\hline
\end{tabular}

Fonte: dados da pesquisa, 2012.

Para o comprometimento organizacional afetivo, percebe-se uma significância de 0,16 (valor de $p \geq 0,05$ ). Portando, aceita-se a hipótese nula, indicando que não existe uma diferença significativa entre os dois grupos de trabalhadores.

Trabalhadores com contratos efetivos e autônomos apresentam uma média de comprometimento organizacional instrumental aproximado, tendo em vista a significância de $(0,13)$ (valor de $p \geq 0,05)$, dessa forma, aceita-se a hipótese nula, o que indica a inexistência de diferenças estatisticamente significantes entre grupos.

Em síntese, os testes de variância apresentados na Tabela 2 demonstram que, no que tange ao comprometimento organizacional afetivo e instrumental, tanto autônomos quanto efetivos denotam uma média similar de comprometimento, sendo que essas médias não possuem diferenças estatísticas significativas. Outros autores também não encontraram diferenças estatisticamente significativas do comprometimento afetivo e instrumental dos trabalhadores quando comparado ao tipo de contrato de trabalho (LEITE, 2004; COSTA, 2005).

É relevante destacar que pesquisas apontam diferenças de comprometimento de acordo com o tipo de contrato de trabalho. Mendes (2007) investigou o comprometimento organizacional em enfermeiras com diferentes vínculos empregatícios, temporárias e 
permanentes, e não encontrou diferenças significativas na base afetiva. No entanto, os permanentes apresentaram maior comprometimento instrumental. Por outro lado, Thompson et al. (1992), na investigação de indivíduos que trabalham em organizações como efetivos e autônomos, apontaram os autônomos como mais comprometidos. Soldi (2006), que investigou o comprometimento de trabalhadores terceirizados e efetivos em uma empresa de telefonia, obteve índices de comprometimento afetivos mais elevados entre os efetivos e um número maior de comprometimento instrumental entre os terceirizados.

\section{CONSIDERAÇÕES FINAIS}

Considerando que a presente pesquisa teve como objetivo analisar as diferenças do comprometimento afetivo e instrumental dos trabalhadores autônomos e efetivos de salões de beleza, as análises realizadas não encontraram diferenças estatísticas significativas do comprometimento afetivo e instrumental entre autônomos e efetivos. No entanto, encontram-se disponíveis na literatura alguns estudos similares sobre comprometimento em trabalhadores com diferentes tipos de contrato de trabalho, cujos resultados denotam variação significativa. Essas diferenças fragilizariam qualquer tentativa de generalização relacionando o comprometimento organizacional e o tipo de contrato de trabalho, porém, abrem espaço para novas pesquisas.

Ao analisar comparativamente as medidas de comprometimento instrumental e afetivo de acordo com a função ocupada, pode-se constatar que funções com atividades mais rotineiras, menos desafiantes e que exigem uma menor variedade de habilidades, como é o caso de manicures, telefonistas e recepcionistas, tendem a diminuir o comprometimento do trabalhador. Os maiores índices de comprometimento referem-se à função de depiladora, com 6,45 (vínculo efetivo) e esteticista com 5,87 (vínculo autônomo).

Das limitações apontadas nesta pesquisa, citam-se os poucos achados da literatura que investigam o contexto do comportamento organizacional em profissionais da área da beleza, fato que dificultou a construção teórica e impediu a comparação dos resultados encontrados com uma amostra de mesmo perfil.

Outra limitação foi a amostra escolhida: salões de beleza de médio porte da cidade de Florianópolis. Percebe-se que a maior parte dos salões de beleza é de pequeno porte, muitos provavelmente possuem políticas diversas de contratação, levando a um diferente perfil de trabalhadores. Tal fato acabou minimizando a possibilidade de generalização da população de trabalhadores de salões de beleza.

No decorrer desse estudo, surgiram outras indagações a respeito do comprometimento organizacional, ficando aqui a indicação para futuras pesquisas: analisar correlatos do comprometimento dos trabalhadores dos salões de beleza, como a satisfação no trabalho e a motivação; analisar como o comprometimento com o trabalho influencia na produtividade dos profissionais autônomos e, consequentemente, na renda obtida através de sua produção.

Ao final, espera-se que a pesquisa realizada tenha contribuído com os estudos acerca do comprometimento organizacional em profissionais com diferentes tipos de contratos de trabalho. Espera-se também que auxilie os gestores dos salões de beleza a compreenderem como se dão os vínculos afetivos e cognitivos dos profissionais que compõem sua organização. 


\section{REFERÊNCIAS BIBLIOGRÁFICAS}

1. ALLEN, N. J.; MEYER, J. P. A three-component conceptualization of organizational commitment in Human. Resource Management Review, v. 69, n. 3, p. 61-89, 1991.

2. ABHIPEC ASSOCIAÇÃO BRASILEIRA DA INDÚSTRIA DE HIGIENE PESSOAL, PERFUMARIA E COSMÉTICOS (2011). Panorama do Setor 2010-2011. São Paulo, n. 12, 2011.

3. ASSOCIAÇÃO NACIONAL DO COMÉRCIO DE ARTIGOS DE HIGIENE PESSOAL E BELEZA. O mercado da beleza brasileiro. Disponível em: http://www.anabel.org.br/?id=aanabel Acesso em: 15 jul. 2012.

4. BARBETTA, P. A. Estatística aplicada às ciências sociais. Florianópolis, UFSC, 2004.

5. BASTOS, A. V. B. Comprometimento organizacional: um balanço dos resultados e desafios que cercam essa tradição de pesquisa. Revista de Administração de Empresas, v. 33, n. 3, p. 52-64, 1993.

6. BASTOS, A. V. B. Comprometimento no trabalho: a estrutura dos vínculos do trabalhador com a organização, a carreira e o sindicato. Tese (Doutorado). Departamento de Psicologia da Universidade de Brasília, 1994.

7. BASTOS, A. V. B. Cognição nas Organizações de Trabalho. In: ZANELLI, J. C., BORGESANDRADE, J. E.; BASTOS, A. V. B. (Org.) Psicologia, organizações e trabalho e no Brasil. Porto Alegre: Artmed, 2004.

8. BASTOS, A. V. B.; MENEZES, I. G. Bases sociológicas, antropológicas e psicológicas do comprometimento organizacional. Psicologia em Revista, Belo Horizonte, n. 12, p.200-215, 2009.

9. BASTOS, A.; ROWE, D. Vínculos com a Carreira e Produção Acadêmica: comparando docentes de IES públicas e privadas em Revista de Administração Contemporânea - RAC, v. 14, n. 6, p. 1011-1030, 2010.

10. BECKER, H. S. Notes on the concept of commitment. American Journal of Sociology, v. 32, p. 341-347, 1969.

11. BORGES-ANDRADE, J. E.; AFANASIEF, R. S.; SILVA, M. S. Mensuração de comprometimento organizacional em instituições públicas. In: Reunião Anual de Psicologia, 19, Ribeirão Preto. Anais... Ribeirão Preto: Sociedade de Psicologia de Ribeirão Preto, p. 236, 1989.

12. BORGES-ANDRADE, J. E. Conceituação e mensuração de comprometimento organizacional. In: Reunião Anual de Psicologia, 23, Ribeirão Preto. Anais tema em psicologia, Ribeirão Preto, v, 2, n. 1, p. 37-47, 1994.

13. COHEN, A. Multiple Commitments in workplace: na inegrative approach. Mahwah, New Jersey: Lawrence Erlbaum Associates, 2003.

14. COOPER-HAKIM, A.; VISWESVARAM, C. The construct of work commitment: Testing an integrative framework. Psychological Bulletin, 131(2), p. 241-259, 2005.

15. COSTA, F. Múltiplos Comprometimento no Trabalho: identificando padrões no trabalho e explorando antecedentes entre trabalhadores de organizações agrícolas. 179 f. Dissertação (Mestrado) - UFBA, Salvador, 2005.

16. COSTA, F. M.; BASTOS, A. V. B. Múltiplos comprometimentos no trabalho: um estudo entre 
trabalhadores de organizações agrícolas do polo de fruticultura irrigada de Juazeiro/Petrolina. Revista de Administração Ufsm, p. 280-297, 2009.

17. HREBINIAK, L.; ALLUTO, J. Personal and role-related factors in the development of organizational commitment. Administrative Science Quarterly, v. 17, p. 555-573, 1972.

18. KELMAN, H. Compliance, Identification, and Internalization: Three Processes of Attitude Chang. Journal Of Conflict Resolution, California, p. 51-60. (1958).

19. LEITE, C. F. F. O comprometimento organizacional na gestão pública: Um estudo de caso em uma universidade estadual. 214f. Dissertação (mestrado) - Escola de Administração, Universidade Federal da Bahia - UFBA, Vitória da Conquista, 2004.

20. MATHIEU, J. E.; ZAJAC, D. M. A review and meta-analysis of the antecedents, correlates, and consequences of organizational commitment. Psychological Bulletin, v. 108, n. 2, p. 171-194, 1990.

21. MEDEIROS, C. A.; ENDERS, W. T. Validação do modelo de conceitualização de três componentes do comprometimento organizacional de Meyer e Alleb: um estudo dos padrões de comprometimento organizacional e suas relações com a performance no trabalho. In: Encontro da ANPAD, 21. Rio das Pedras. Anais. Rio das Pedras: ANPAD, 1997. CD-ROOM, 1997.

22. MEDEIROS, C. A Comprometimento Organizacional, características pessoais e performance no trabalho: um estudo dos padrões de Comprometimento Organizacional. $157 \mathrm{f}$. Dissertação de Mestrado. Centro de Ciências Sociais Aplicadas da UFBA, Natal, 1997.

23. MEDEIROS, C. A.; AlBUQUERQUE, L. G.; SIQUEIRA, M.; MARQUES, G. M. Comprometimento Organizacional: Um Estudo Exploratório de Seus Múltiplos Componentes. In: Encontro da Associação Nacional dos Programas de Pós-Graduação em Administração, 27, Atibaia. Anais... ENAPAD: Atibaia. P. 45-55, 2003.

24. MELCHOR, P. Novas regras para prorrogação dos contratos de trabalho temporário". Disponível em: http://natal.sp.sebrae.com.br/prorrogacao_contrato_ trabalho.asp. Acesso em: 15 out. 2012.

25. MENDES, V. L.; ZATTI, M. L. Comprometimento Organizacional na Área Hospitalar e Vínculos Empregatícios. In: ENCONTRO ANUAL DA ANPAD, 21, Rio de Janeiro. Anais... Rio de Janeiro: ANPAD. 1 CD-ROOM, 2007.

26. MENEZES, I. G. Comprometimento organizacional: construindo um conceito que integra atitudes e intenções comportamentais. 203 f. Tese (doutorado) da Universidade Federal da Bahia, Salvador, 2009.

27. MEYER, J. P; ALLEN, N. J. Commitment in the workplace: Theory, research, and application. Thousand Oaks: Sage Publications, 1997.

28. MEYER, J. P.; IRVING, G.; ALLEN, N. J. Examination of the combined effects of work values and early work experiences on organizational commitment. Journal of Organizational Behavior, v. 19, n. 2, p. 29-52, 1998.

29. MEYER, J. P.; STANLEY, D.; HERCSOCOVICH, L.; TOPOLNYTSKY, L. Affective, Continuance and Normative Commitment to the Organization: A Meta-analysis of Antecedents, Correlates, and Consequences. Journal of Vocational Behavior, v. 61, n. 1, p. 20-52, 2002.

30. MOSCON, D. B. Teorias implícitas de trabalhador comprometido e estratégias cotidianas de 
gestão: uma análise qualitativa. 121 f. Dissertação. Mestrado em Administração Universidade Federal da Bahia, Salvador, 2009.

31. MOWDAY, R.; STEERS, R.; PORTER, L. The measurement of organizational commitment. Journal of Vocational Behavior, v. 14, n. 19, p. 224-247, 1979.

32. MOWDAY, R.; STEERS, R.; PORTER, L. Employee-organization linkages: The psychology of commitment, absenteeism, and turnover. New York: Academic Press, 1982.

33. NASCIMENTO, A. M. Curso de Direito do Trabalho. São Paulo: Saraiva, 2010.

34. RITZER, G.; TRICE, H. An empirical study of Howard Becker's side-bet theory. Social Forces, v. 47, p. 475-479, 1969.

35. SINBEL, Sindicato Dos Institutos de Beleza e Cabeleireiros de Senhoras do Rio de Janeiro. Condições de trabalho dos integrantes da categoria para o período de 2010. Disponível em: <http://www.sinbel.com.br/diversos23.htm>. Acesso em: 10 dez. 2012.

36. SIQUEIRA, M. M. M. Comprometimento organizacional afetivo, calculativo e normativo: evidências acerca da validade discriminante de três medidas brasileiras. In: Encontro da ANPAD, 25, Campinas. Anais... Campinas: ENANPAD. CD-ROOM, 2001.

37. SIQUEIRA, M. M. M.; GOMIDE J. S. Vínculos do indivíduo com o trabalho e com a organização. In: ZANELLI J. C.; BORGES-ANDRADE J. E.; BASTOS A. V. B. (Orgs.), Psicologia, organizações e trabalho no Brasil, São Paulo: Artmed, p. 144-301, 2004.

38. SOLDI, R. M. O comprometimento organizacional de trabalhadores terceirizados e efetivos: Um estudo comparativo em uma empresa de telefonia. $147 \mathrm{f}$. Dissertação (Mestrado em Administração) Universidade Federal de Santa Catarina, Florianópolis, 2006.

39. TAMAYO, Á.; SOUZA, M. G. S.; VILAR, L. S.; RAMOS, J. L.; ALBERNAZ, J. V.; FERREIRA, N. P. Prioridades axiológicas e comprometimento organizacional em Psicologia: teoria e pesquisa, v. 17, n. 1, p. 27-35, 2001.

40. THOMPSON, C.; KOPELMAN, R.; SCHRIESHEIM, C. Putting All One. Journal of Applied Psychology, n. 5, p. 738-743, 1992.

41. ZANELLI, J. C.; SILVA, N. Interação humana e gestão: a construção psicossocial das organizações de trabalho. São Paulo, 2008. 